\title{
ORIGINAL ARTICLE \\ Effects of solifenacin in patients with neurogenic detrusor overactivity as a result of spinal cord lesion
}

\author{
$\mathrm{J} \mathrm{Krebs}^{1}$ and J Pannek ${ }^{2}$
}

\begin{abstract}
Study design: Retrospective analysis.
Objectives: To investigate the urodynamic effects of solifenacin treatment for neurogenic detrusor overactivity (NDO) in patients with spinal cord injury (SCI).

Setting: Paraplegic center in Switzerland.

Methods: Retrospective analysis of case histories and urodynamic data of $35 \mathrm{SCl}$ patients receiving solifenacin for treatment of NDO between 2008 and 2012. Patients were categorized as being at risk of renal damage when maximum detrusor pressure was $>40 \mathrm{~cm}$ $\mathrm{H}_{2} \mathrm{O}$ or detrusor compliance was $<20 \mathrm{ml} \mathrm{cm}^{-1} \mathrm{H}_{2} \mathrm{O}$.

Results: Solifenacin treatment was initiated 7.3 years after $\mathrm{SCl}$. Most patients (63\%) had already been taking other antimuscarinic drugs. After 13.1 months (median, interquartile range 6.1-19.5 months), solifenacin treatment had resulted in significant $(P<0.03)$ improvements in bladder capacity (median $+30.0 \mathrm{ml}$ ), maximum detrusor pressure (median $\left.-7.0 \mathrm{~cm} \mathrm{H}_{2} \mathrm{O}\right)$, reflex volume $($ median $+62.5 \mathrm{ml}$ ) and detrusor compliance (median $+25.0 \mathrm{ml} \mathrm{cm}^{-1} \mathrm{H}_{2} \mathrm{O}$ ). Furthermore, fewer patients presented with a risk of renal damage. However, this difference was not significant $(P>0.1)$. The number of patients suffering from incontinence had not changed significantly. Eight and two patients discontinued solifenacin treatment as a result of insufficient efficacy and intolerable adverse events, respectively. One patient had discontinued solifenacin treatment without further explanation.
\end{abstract}

Conclusion: Solifenacin treatment significantly improved bladder capacity, detrusor compliance, reflex volume and maximum detrusor pressure. Solifenacin treatment seems to be an effective oral treatment of NDO after SCI.

Spinal Cord (2013) 51, 306-309; doi:10.1038/sc.2012.164; published online 18 December 2012

Keywords: neurogenic lower urinary tract dysfunction; urodynamics; solifenacin; spinal cord injury

\section{INTRODUCTION}

Neurogenic lower urinary tract dysfunction (NLUTD) affects the majority of patients with spinal cord injury (SCI). The main concern in these patients is renal damage as a result of high detrusor storage and voiding pressures, ${ }^{1}$ which used to be the most common cause of mortality in SCI. ${ }^{2}$ High detrusor pressures result from detrusor overactivity or low bladder compliance, often combined with detrusor-sphincter-dyssynergia. ${ }^{3}$ Antimuscarinic drugs have therefore become the first-line treatment for alleviating neurogenic detrusor overactivity (NDO). ${ }^{3,4}$ The control of storage and voiding detrusor pressures has resulted in lower mortality rates from urological causes in SCI patients. ${ }^{5}$ The efficacy and safety of antimuscarinic drugs, such as oxybutynin, trospium chloride, tolterodine and propiverine, for the long-term treatment of NDO is well established., ${ }^{4,6}$ The antimuscarinic treatment of NDO in SCI patients lasts commonly lifelong, and thus compliance with therapy is an important issue. Unfortunately, SCI patients tend to require higher doses of antimuscarinic drugs than those with idiopathic detrusor overactivity, ${ }^{4}$ which in turn may lead to more or more severe adverse events $^{7}$ and consequently to abortion of treatment. ${ }^{4,6,8}$

Solifenacin is a once daily oral antimuscarinic drug with a high affinity for the $\mathrm{M}_{3}$ muscarinic receptor in the bladder, which is regarded to be the main mediator of detrusor contractility. ${ }^{9}$ Solifenacin has been reported to be more effective (quality of life, patient reported cure, incontinence and urgency episodes) and cause fewer adverse events and thus fewer withdrawals than other antimuscarinic drugs in patients with idiopathic overactive bladder. ${ }^{10}$ To date, there is no data on the efficacy of solifenacin in the treatment of NDO as a result of SCI. In a study with patients suffering from multiple sclerosis, solifenacin significantly improved voiding frequency, severity of urgency and incontinence. ${ }^{11}$ However, no urodynamic data had been reported. We therefore investigated the urodynamic effects of solifenacin treatment for NDO in patients with SCI.

\section{MATERIALS AND METHODS}

This retrospective study was approved by the local Ethics Committee, and all patient data were made anonymous and kept confidential. We certify that all applicable institutional and governmental regulations concerning the ethical use of the data were followed during the course of this research.

The case histories of all patients being treated with solifenacin (Vesicare, Astellas Pharma, Wallisellen, Switzerland) for NLUTD following SCI and undergoing urodynamic examination at our institution between January 2008 and March 2012 were reviewed. A total of 41 patients were identified.

The patient characteristics, type of NLUTD, bladder diary details (includng number of incontinence pads and urinary tract infections), drugs with known relevant impact on detrusor function and urodynamic data (bladder capacity, maximum detrusor pressure during the storage phase, detrusor compliance and reflex volume) were collected. Patients were categorized as being at risk of 
renal damage if maximum detrusor pressure was $>40 \mathrm{~cm} \mathrm{H}_{2} \mathrm{O}$ or detrusor compliance was $<20 \mathrm{ml} \mathrm{cm}^{-1} \mathrm{H}_{2} \mathrm{O}^{12}$

Urodynamic examination was performed with the patient in supine position. An 8-French transurethral double-lumen catheter and a 14-French indwelling rectal catheter were used for the measurement of intravesical and rectal pressure, respectively. The bladder was filled with sterile $0.9 \%$ saline solution at body temperature with a filling rate of $20 \mathrm{ml} \mathrm{min}^{-1}$. Intravesical and rectal pressure were measured by Statham pressure transducers, and the data were recorded by a standard urodynamic software (Medical Measurement Systems, Gladbeck, Germany). Suprapubic tapping was used as a standard provocative maneuver at the end of the examination. Measurement and evaluation of the urodynamic parameters were performed according to the current International Continence Society standards. ${ }^{13}$ The following urodynamic parameters were evaluated: bladder capacity, detrusor compliance, maximum detrusor pressure during the storage phase and reflex volume, if applicable.

The data were calculated and presented as the median and the interquartile range (IQR). The differences between independent and dependent samples were tested with the Mann-Whitney $U$ and the Wilcoxon signed-rank test, respectively. The $\chi^{2}$ and Fisher's exact test were used to test differences in the observed frequency distribution between groups. Statistical analyses were performed using the SPSS software (version 18.0.3, IBM, Somers, NY, USA). A $P$-value of $<0.05$ was considered significant.

\section{RESULTS}

The data of 41 SCI patients being treated with solifenacin for NDO were screened for exclusion criteria. Six patients were excluded: three were using suprapubic catheters, two had additionally received botulinum toxin injections into the detrusor muscle and one had been lost to follow-up.

The etiology of SCI in the remaining 35 patients $(25$ males and 7 females) was predominately trauma $(n=30,85.7 \%)$. There were three patients with myelomeningocele, as well as one patient each with vascular and uncertain etiology. There were 4 tetraplegic and 31 paraplegic patients. The majority of patients $(n=32,91.4 \%)$ suffered from suprasacral lesions. SCI was complete in 15 and incomplete in 20 patients, respectively. All patients suffered from urodynamically confirmed NDO. There were no statistically significant differences between the urodynamic values of the traumatic and the nontraumatic SCI patients $(P>0.2)$ nor between values of the patients with prior antimuscarinic treatment and those without $(P>0.1)$.
Thus, the data were pooled for analysis and presentation (Table 1). The majority of patients $(n=22,62.9 \%)$ suffered from NDO despite oral antimuscarinic medication before solifencain treatment: tolterodine $(n=14)$, oxybutynin $(n=6)$, darifenacin $(n=1)$ and trospium chloride $(n=1)$. Most patients $(n=32,91.4 \%)$ used intermittent catheterization for bladder evacuation, whereas three patients emptied the bladder with the help of the Valsalva maneuver.

The indications for solifenacin treatment initiation are listed in Table 2. Solifenacin treatment was initiated 7.3 years (median, IQR 2.7-22.0 years) after SCI. The median age of the patients at the treatment initiation was 44.9 years (IQR 34.4-56.3 years). The majority of patients $(n=33,94.3 \%)$ was taking $10 \mathrm{mg}$ solifenacin daily, two were taking $5 \mathrm{mg}$. The most recent follow-up data was collected 13.1 months (median, IQR 6.1-19.5 months) after treatment initiation. In all, 4 patients were also taking pregabalin $(n=3)$ or gabapentin $(n=1)$, and 10 patients were taking antispastic medication: baclofen $(n=4)$, tizanidine $(n=2)$ or both $(n=1)$. No further medication with antimuscarinic activity was taken. The dosage of these drugs remained stable during the follow-up period.

Table 2 Indications for solifenacin treatment initiation

\begin{tabular}{lrc}
\hline Indication & Count & Frequency (\%) \\
\hline NDO & 14 & 40.0 \\
Low compliance & 9 & 25.7 \\
Antimuscarinic drug side effects & 6 & 17.1 \\
Incontinence & 5 & 14.3 \\
Low capacity & 2 & 5.7 \\
Detrusor-sphincter-dyssynergia & 1 & 2.5 \\
Bladder spasms & 1 & 2.5 \\
Urgency & 1 & 2.5 \\
Patient's request & 1 & 2.5 \\
Unknown & 8 & 22.9
\end{tabular}

Abbreviation: NDO, neurogenic detrusor overactivity.

Listed indications for solifenacin treatment initiation in the 35 patients. A given indication may have been present in several patients and thus the sum of the count and the frequency exceed $35 \%$ and $100 \%$, respectively.

Table 1 Urodynamic and voiding diary data before and under solifenacin treatment

\begin{tabular}{|c|c|c|c|c|}
\hline & Before solifenacin treatment & Under solifenacin treatment & $P$ & $\mathrm{n}$ \\
\hline Maximum detrusor pressure $\left(\mathrm{cm} \mathrm{H}_{2} \mathrm{O}\right)$ & $33(18-50)$ & $20(10-32)$ & 0.001 & 35 \\
\hline Overactivity volume (ml) & $216(168-304)$ & 301 (157-334) & 0.02 & 29 \\
\hline Capacity (ml) & $404(270-480)$ & $430(346-500)$ & 0.000 & 35 \\
\hline Detrusor compliance $\left(\mathrm{ml} \mathrm{cm}^{-1} \mathrm{H}_{2} \mathrm{O}\right)$ & $38(16-71)$ & $63(20-95)$ & 0.003 & 35 \\
\hline Patients with risk of renal damage ${ }^{a}$ & 17 & 12 & 0.33 & 35 \\
\hline $\begin{array}{l}\text { Maximum detrusor pressure } \\
>40 \mathrm{~cm} \mathrm{H}_{2} \mathrm{O} \text { (patients) }\end{array}$ & 13 & 6 & 0.12 & 35 \\
\hline $\begin{array}{l}\text { Detrusor compliance } \\
<20 \mathrm{ml} \mathrm{cm}^{-1} \mathrm{H}_{2} \mathrm{O} \text { (patients) }\end{array}$ & 11 & 8 & 0.59 & 35 \\
\hline Urinary incontinence (patients) & 19 & 16 & 0.8 & $32 \dagger$ \\
\hline Absorptive pads ( $n$ per day) & $1(0-4)$ & $0(0-2)$ & - & 27 \\
\hline Recurrent ( $>2$ per year) lower urinary tract infections (patients) & 14 & 13 & - & 35 \\
\hline Frequency of voiding (IC; $n$ per day) & $6(5-8)$ & $6(5-7)$ & - & $32^{b}$ \\
\hline
\end{tabular}

Abbreviations: IC, intermittent catheterization; IQR, interquartile range.

The values are given as the median and the IQR where appropriate.

a Maximum detrusor pressure $>40 \mathrm{~cm} \mathrm{H}_{2} \mathrm{O}$ or detrusor compliance $<20 \mathrm{ml} \mathrm{cm}^{-1} \mathrm{H}_{2} \mathrm{O}$.

bOnly patients voiding with IC. 
Solifenacin treatment resulted in significant improvements in all urodynamic parameters (Figure 1): bladder capacity $+30.0 \mathrm{ml}$ (median, IQR $0.0-69.0 \mathrm{ml}$ ), maximum detrusor pressure $-7.0 \mathrm{~cm}$ $\mathrm{H}_{2} \mathrm{O}$ (median, IQR -17.0 to $-1.0 \mathrm{~cm} \mathrm{H}_{2} \mathrm{O}$ ), reflex volume $+62.5 \mathrm{ml}$ (median, IQR 12.5-101.0 ml) and detrusor compliance + $25.0 \mathrm{ml} \mathrm{cm}^{-1} \mathrm{H}_{2} \mathrm{O}$ (median, IQR -1.0 to $50.0 \mathrm{ml} \mathrm{cm}^{-1} \mathrm{H}_{2} \mathrm{O}$ ). Furthermore, fewer patients presented with a risk of renal damage ( 6 vs 13 based on maximum detrusor pressure, 8 vs 11 based on detrusor compliance; Table 1). However, these differences were not significant $(P>0.1)$. There was no difference between the number of absorptive pads used or the daily frequency of intermittent catheterization for bladder evacuation before and under solifenacin treatment, and the number of patients suffering from incontinence remained virtually unchanged (16 vs 19 ; Table 1 ).

Four of the six patients, who received solifenacin because of intolerable adverse events of their current antimuscarinic drug, reported no adverse events under solifenacin. However, three patients, who had not complained of antimuscarinic drug adverse events previously, experienced adverse events under solifenacin. In one of these patients, adverse events were intolerable and resulted in treatment termination. The documented adverse events of solifenacin were: dry mouth $(n=2)$, and fatigue $(n=2)$; in one patient adverse events were not specified.

In 11 patients (31.4\%), solifenacin treatment was discontinued: in 6 (17.1\%) and 2 patients $(5.7 \%)$ as a result of insufficient efficacy and intolerable adverse events, respectively. Of these patients, two received other antimuscarinic drugs, four were treated by botulinum toxin injection in the detrusor and one received electro-motive drug administration. In another patient, neuromodulation was recommended. Three patients had terminated solifenacin medication without further explanation.

\section{DISCUSSION}

This is the first study reporting on the urodynamic effects of solifenacin treatment for NDO in patients with SCI. Solifenacin treatment resulted in significant improvements in all urodynamic parameters: detrusor compliance increased by $66 \%$, reflex volume by $39 \%$, bladder capacity by $6 \%$ and maximum detrusor pressure decreased by $39 \%$. Furthermore, fewer patients presented with a risk of renal damage or incontinence, although these trends did not reach statistical significance. The majority of patients (69\%) continued solifenacin treatment.

To the best of our knowledge, there is no published manuscript describing the urodynamic effects of solifenacin in patients with NLUTD due to SCI. In the only study including some patients with NDO, bladder capacity at the time when patients felt a strong desire to void was significantly increased (by $27 \%$ from 297 to $378 \mathrm{ml}$ ) in 52 female patients with overactive bladder symptoms, who were treated with $5 \mathrm{mg}$ of solifenacin. ${ }^{14}$ However, intravesical pressure was not significantly decreased in these patients. Unfortunately, the results were not presented separately for patients with overactive bladder symptoms of neurogenic and idiopathic origin, respectively. In another study evaluating the effects of solifenacin on patients with $\mathrm{NDO}$ as a result of multiple sclerosis, no urodynamic data were evaluated. ${ }^{11}$

Studies evaluating the urodynamic effects of solifenacin in idiopathic detrusor overactivity, most commonly summarized under 'overactive bladder syndrome', are rare. This may at least partially be the result of the fact that overactive bladder syndrome in nonneurogenic patients is a clinical diagnosis, not involving urodynamic measurements. ${ }^{15}$ In one of the few urodynamic-based studies in patients suffering from overactive bladder syndrome, Lowenstein et al. ${ }^{16}$ have reported a $41 \%$ increase in bladder capacity in 10 women treated with $10 \mathrm{mg}$ of solifenacin. In contrast, Hsiao et al. ${ }^{17}$ have not observed any changes in detrusor pressure at maximal flow rate or bladder capacity at strong desire to void in 21 female patients with overactive bladder syndrome under solifenacin treatment.

In this study, fewer patients (12 vs 17) presented with a risk of renal damage under solifencain treatment. Although this difference, most probably as a result of the limited number of patients included, was

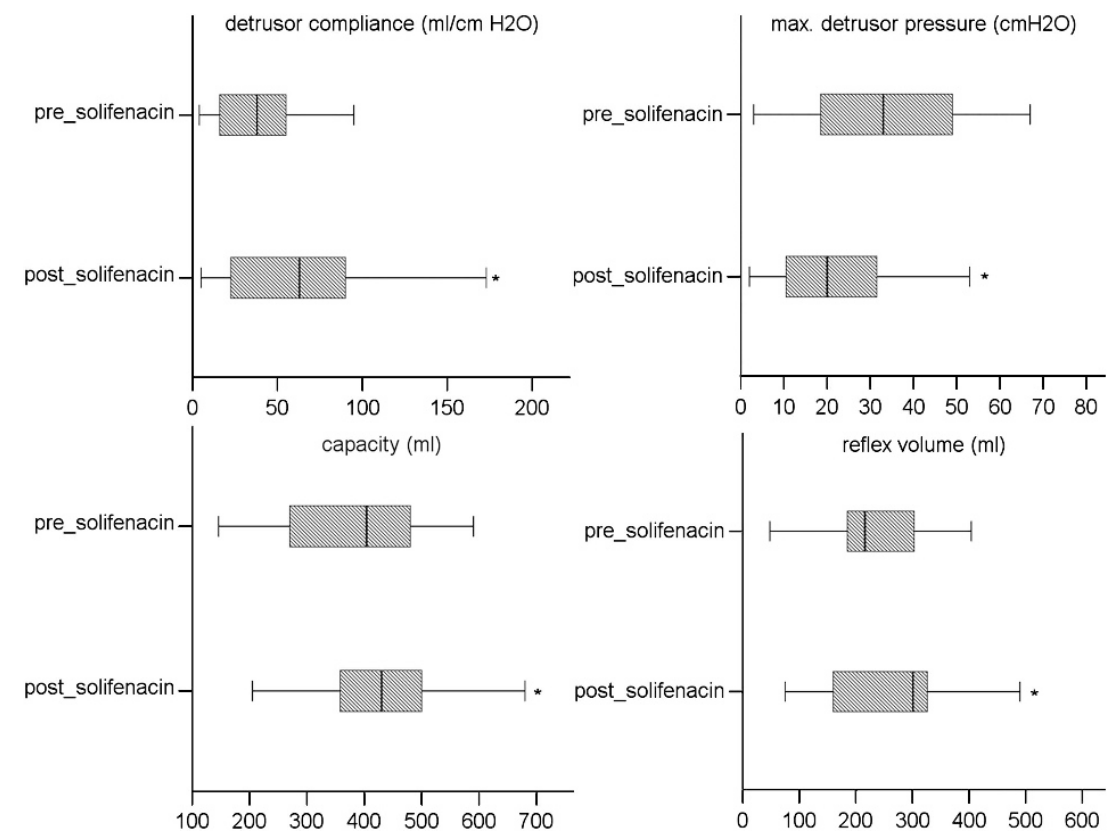

Figure 1 Box plots of bladder capacity, detrusor compliance, reflex volume and maximum (max.) detrusor pressure before (pre_solifenacin) and under solifenacin (post_solifenacin) treatment. ${ }^{*}$ Significantly $(P<0.021)$ different from pre_solifenacin value. 
not significant, the data demonstrated that protection of renal function, the ultimate goal of NLUTD treatment in patients with SCI, can be achieved by solifenacin in a substantial number of patients. As solifenacin was administered as a second-line treatment in the majority of patients $(n=22,63 \%)$, solifenacin was effective in a substantial number of patients even though other antimuscarinic medication had failed previously.

In this study, solifenacin treatment did not reduce the number of patients suffering from incontinence, the number of absorptive pads used or the daily frequency of intermittent catheterization for bladder evacuation. However, in NLUTD after SCI, incontinence is often multifactorial and is not always caused by NDO alone. Therefore, even after effective treatment of NDO by solifenacin, incontinence may persist. Furthermore, clinical symptoms are not reliable for the assessment of severity of NDO or the risk of renal damage. Regular urodynamic evaluation is warranted to ensure prevention of upper urinary tract damage. ${ }^{4,18}$

In this study, two patients (6\%) discontinued solifenacin treatment as a result of intolerable adverse events. Four of the six patients $(67 \%)$, who had received solifenacin because of intolerable adverse events of their previous antimuscarinic drug, reported no adverse events under solifenacin. The recorded adverse events were dry mouth and fatigue. The percentage of treatment discontinuation as a result of intolerable adverse events reported in the literature is similar to our results for $10 \mathrm{mg}$ solifencain. ${ }^{11,19,20}$ Gastrointestinal (dry mouth and constipation) and eye disorders (blurred vision) were the most commonly reported side effects. ${ }^{20}$ The abortion rate in our study was very similar to the one reported by van Rey et al. ${ }^{11}$ in patients suffering from NDO following multiple sclerosis.

The urodynamic results of antimuscarinic treatment of NDO in patients with SCI vary widely between studies. As all studies differ significantly regarding inclusion and exclusion criteria and duration of treatment, merely head-to-head comparisons can reliably compare the efficacy and tolerability of different antimuscarinic drugs. However, our results compare favorably to previously published data in this cohort of patients. ${ }^{6}$

The limited number of patients and the retrospective design pertain to the limitations of this study. However, this is the first investigation of the urodynamic effects of solifenacin treatment in patients suffering from NDO following SCI. As solifenacin is not licensed for the treatment of NDO, we exclusively use the substance as a second-line treatment, which may have resulted in an underestimation of its effectiveness. Based on the encouraging results of our study concerning both effectiveness and tolerability, prospective randomized placebo-controlled studies of solifenacin as a first-line treatment for NDO after SCI should be conducted.

\section{DATA ARCHIVING}

There were no data to deposit.

\section{CONFLICT OF INTEREST}

The authors declare no conflict of interest.

1 Gerridzen RG, Thijssen AM, Dehoux E. Risk factors for upper tract deterioration in chronic spinal cord injury patients. J Urol 1992; 147: 416-418.

2 Hackler $\mathrm{RH}$. A 25-year prospective mortality study in the spinal cord injured patient: comparison with the long-term living paraplegic. J Urol 1977; 117: 486-488.

3 Burns AS, Rivas DA, Ditunno JF. The management of neurogenic bladder and sexual dysfunction after spinal cord injury. Spine 2001; 26: S129-S136.

4 Stohrer M, Blok B, Castro-Diaz D, Chartier-Kastler E, Del Popolo G, Kramer G et al. EAU guidelines on neurogenic lower urinary tract dysfunction. Eur Urol 2009; 56: 81-88.

5 Frankel HL, Coll JR, Charlifue SW, Whiteneck GG, Gardner BP, Jamous MA et al. Longterm survival in spinal cord injury: a fifty year investigation. Spinal Cord 1998; 36: 266-274.

6 del Popolo G, Mencarini M, Nelli F, Lazzeri M. Controversy over the pharmacological treatments of storage symptoms in spinal cord injury patients: a literature overview. Spinal Cord 2012; 50: 8-13.

7 Kessler TM, Bachmann LM, Minder C, Löhrer D, Umbehr M, Schünemann HJ et al. Adverse event assessment of antimuscarinics for treating overactive bladder: a network meta-analytic approach. PLoS One 2011; 6: e16718.

8 Benner JS, Nichol MB, Rovner ES, Jumadilova Z, Alvir J, Hussein M et al. Patientreported reasons for discontinuing overactive bladder medication. BJU Int 2010; 105: $1276-1282$.

9 Ohtake A, Saitoh C, Yuyama H, Ukai M, Okutsu H, Noguchi Y et al. Pharmacological characterization of a new antimuscarinic agent, solifenacin succinate, in comparison with other antimuscarinic agents. Biol Pharm Bull 2007; 30: 54-58.

10 Madhuvrata P, Cody JD, Ellis G, Herbison GP, Hay-Smith EJ. Which anticholinergic drug for overactive bladder symptoms in adults. Cochrane Database Syst Rev 2012; 1: CD005429.

11 van Rey F, Heesakkers J. Solifenacin in multiple sclerosis patients with overactive bladder: a prospective study. Adv Urol 2011; 2011: 834753

12 Stohrer M, Goepel M, Kondo A, Kramer G, Madersbacher H, Millard R et al. The standardization of terminology in neurogenic lower urinary tract dysfunction: with suggestions for diagnostic procedures. International Continence Society Standardization Committee. Neurourol Urodyn 1999; 18: 139-158.

13 Schafer W, Abrams P, Liao L, Mattiasson A, Pesce F, Spangberg A et al. Good urodynamic practices: uroflowmetry, filling cystometry, and pressure-flow studies. Neurourol Urodyn 2002; 21: 261-274.

14 Tanaka Y, Masumori N, Tsukamoto T. Urodynamic effects of solifenacin in untreated female patients with symptomatic overactive bladder. Int J Urol 2010; 17: 796-800.

15 Abrams P, Cardozo L, Fall M, Griffiths D, Rosier P, Ulmsten U et al. The standardisation of terminology in lower urinary tract function: report from the standardisation sub-committee of the International Continence Society. Urology 2003; 61: 37-49.

16 Lowenstein L, Kenton K, Mueller ER, Brubaker L, Sabo E, Durazo-Arivzu RA et al. Solifenacin objectively decreases urinary sensation in women with overactive bladder syndrome. Int Urol Nephrol 2012; 44: 425-429.

17 Hsiao SM, Chang TC, Wu WY, Chen CH, Yu HJ, Lin HH. Comparisons of urodynamic effects, therapeutic efficacy and safety of solifenacin versus tolterodine for female overactive bladder syndrome. J Obstet Gynaecol Res 2011; 37: 1084-1091.

18 Nosseir M, Hinkel A, Pannek J. Clinical usefulness of urodynamic assessment for maintenance of bladder function in patients with spinal cord injury. Neurourol Urodyn 2007; 26: 228-233.

19 Chapple CR, Martinez-Garcia R, Selvaggi L, Toozs-Hobson P, Warnack W, Drogendijk T et al. A comparison of the efficacy and tolerability of solifenacin succinate and extended release tolterodine at treating overactive bladder syndrome: results of the STAR trial. Eur Urol 2005; 48: 464-470.

20 Choo MS, Lee JZ, Lee JB, Kim YH, Jung HC, Lee KS et al. Efficacy and safety of solifenacin succinate in Korean patients with overactive bladder: a randomised, prospective, double-blind, multicentre study. Int J Clin Pract 2008; 62: 1675-1683. 